\title{
Awareness of Locomotive Syndrome and Factors Associated with Awareness: A Community-Based Cross-Sectional Study
}

\author{
Keiko Sugai $^{1}$ (D), Haruhiko Imamura ${ }^{2, *(\mathbb{D})}$, Takehiro Michikawa ${ }^{2}$, Keiko Asakura ${ }^{2}$ (D) and \\ Yuji Nishiwaki ${ }^{2}$ \\ 1 Department of Orthopaedic Surgery, Keio University School of Medicine, 35 Shinanomachi, Shinjuku, \\ Tokyo 160-8582, Japan; ksugai@keio.jp \\ 2 Department of Environmental and Occupational Health, School of Medicine, Toho University, \\ 5-21-16 Omorinishi, Ota-ku, Tokyo 143-8540, Japan; takehiro.michikawa@med.toho-u.ac.jp (T.M.); \\ keiko.asakura@med.toho-u.ac.jp (K.A.); yuuji.nishiwaki@med.toho-u.ac.jp (Y.N.) \\ * Correspondence: haruhiko.imamura@med.toho-u.ac.jp; Tel.: +81-3-3762-4151
}

Received: 24 September 2020; Accepted: 1 October 2020; Published: 5 October 2020

\begin{abstract}
Locomotive syndrome is a condition of reduced mobility, and patients have a high risk of requiring nursing care. In order to investigate the level of awareness of the term "locomotive syndrome" and the factors relating to awareness in a community, awareness of locomotive syndrome was included in a questionnaire survey on health and daily life conducted in Koumi Town (Japan), which was distributed to 3181 eligible residents aged 40 years or older. Information on age, sex, marital status, educational attainment, lifestyle, and social environment was also collected, and the association of awareness with various factors was analyzed with two multivariable Poisson regression models. As a result, awareness among respondents was $44.6 \%$. Awareness was significantly higher among women, those who were 60-79 years old, married, and had received higher education. Additionally, awareness was significantly associated with social factors, especially attendance at regional events within the last one year, in both women and men: the adjusted prevalence ratios $(95 \%$ confidence intervals) were 1.26 (1.10-1.43) and 1.48 (1.19-1.83), respectively. In conclusion, in addition to strengthen awareness rising campaigns targeting men and for younger people, providing health education at social settings such as regional events may help improve future musculoskeletal health in the elderly.
\end{abstract}

Keywords: locomotive syndrome; elderly health; cross-sectional study; community based study; preventive care

\section{Introduction}

Population ageing is now a global phenomenon. The proportion of population aged 65 years or over increased from 6\% in 1990 to $9 \%$ in 2019, and is projected to rise to $16 \%$ by 2050 [1]. Japanese society is said to be aging at the fastest rate in the world; the proportion of people aged 65 years or over as of 2019 is $28.5 \%$ [2], which is the highest proportion in the world. Ageing of society accompanies a risk to increase financial pressure on old-age support systems. Actually in Japan, there is a gap of 9 to 12 years between healthy life expectancy and average life expectancy, which places a heavy burden on nursing care [3]. Musculoskeletal problems (fractures and articular diseases) are the most common cause of the need for nursing care [4], so the importance of maintaining musculoskeletal health is gathering attention in preventing the care-need.

Locomotive syndrome is a term coined in 2007 by the Japanese Orthopaedic Association [5-9]. It involves reduced mobility due to diminished musculoskeletal performance, and patients have a high 
risk of requiring future nursing care. The progression of locomotive syndrome can be assessed by test composed of two physical exams and one self-reported questionnaire [10]. Using this test, about $81.0 \%$ and $34.1 \%$ of Japanese people at the age of 60 or over are reported be at the 1st (the beginning of decline in mobility) and the 2nd (progressing towards decline in mobility) stage of locomotive syndrome [11], respectively. The prevalence increases with age [12], because the conditions underlying it are more common in older people [6,12]. For example, lumbar spondylosis (Kellgren-Lawrence $>2$ ) is present in $81.5 \%$ of men and $65.5 \%$ of women over 40 years old; the corresponding figures for radiographic knee osteoarthritis are $42.6 \%$ and $62.4 \%$ [13]. In addition to aging, lifestyle factors such as lack of exercise and inadequate nutritional intake also cause progression of locomotive syndrome. Excessive loading and obesity are known to be risk factors for the progression of deformation and impairment of joints and intervertebral disks, and insufficient loading and extreme thinness are risk factors for osteoporosis and sarcopenia [6]. Because the symptoms of the conditions underlying locomotive syndrome appear only after the condition has progressed to some extent, it may be too late to start taking preventive measures after symptoms appear. To effectively prevent physical decline, therefore, preventive measures need to be initiated before the condition progresses, which cannot be achieved without raising public awareness of locomotive syndrome [14].

Many studies have shown the effectiveness of physical interventions in preventing physical decline in elderly people [15-17]; although, their effects are limited for severe disabilities [16]. This points up the importance of implementing preventive measures before the onset of symptoms, or while they are still mild; however, knowledge among the public of the risks of locomotive syndrome is necessary to achieve this. There are many reports that awareness of disease leads to preventive behavior [18-20]. Likewise, awareness of locomotive syndrome is necessary for people to take preventive measure in their daily life.

The Japanese Ministry of Health, Labour, and Welfare aims has set a target of increasing the percentage of individuals who know about locomotive syndrome to $80 \%$ by 2022 from that $17.3 \%$ in 2012 through its national health promotion program "The second term of National Health Promotion in the twenty first century (Health Japan 21 (the second term))" (2013-2022) [6,21]. Awareness-raising activities have succeeded to some extent $[7,22]$, but the level of public awareness of the syndrome has leveled off at around $45 \%$ since 2015 [23,24]. Although it is important to raise awareness of the syndrome to promote preventive action, it is difficult to find effective publicity measures.

In this study, we investigated the level of awareness of locomotive syndrome and the factors associated with awareness in a rural community. We hope that the introduction of our initiatives of super-aging Japanese society will serve as a reference for ageing measures in other countries.

\section{Materials and Methods}

\subsection{Study Population}

This study was performed as part of a questionnaire survey on health and daily life conducted in Koumi Town, Nagano Prefecture. Koumi Town is a mountainous community about $100 \mathrm{~km}$ northwest of Tokyo, Japan, with a population of approximately 4700 and relatively high proportion of people aged 65 and over (39.1\% in 2015). In August 2017, targeting all residents aged 40 years or older who were not certified for nursing care, the questionnaire was distributed to 3316 residents with the support of Koumi Town Hall and health promotion volunteers. Excluding those who were hospitalized or institutionalized, 3181 residents were approached, identified as eligible for participation in the study, and received the questionnaire. By anonymous posting, 1893 of them (59.5\%) returned the questionnaire. Of these respondents, $1804(56.7 \%)$ answered the question about their awareness of locomotive syndrome. In this sample size $(n=1804)$, the awareness proportion of $45 \%[23,24]$ could estimate $95 \%$ confidence interval with less than $5 \%$. The schema of the recruitment of the participants are shown as Figure 1. 


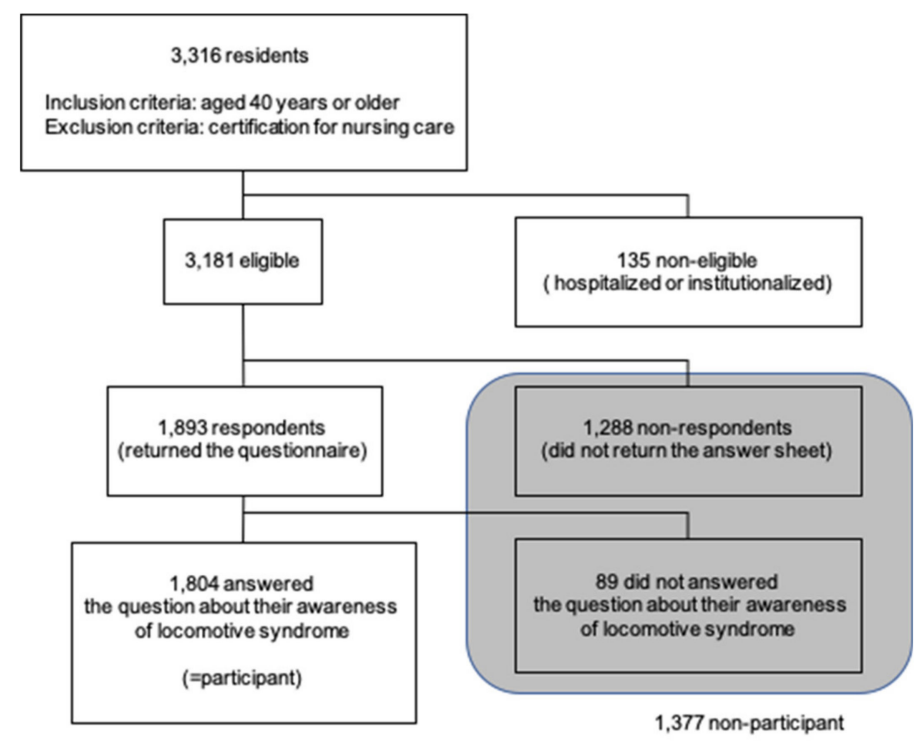

Figure 1. Schema of the recruitment of the participants.

The study protocol was approved by the institutional ethics committee of the Faculty of Medicine, Toho University, Tokyo (Approval No. A19068_A17095_A17048). All participants were informed of the purpose and methods of the study, their right to participate or not, and their right to withdraw; they were also assured of anonymity.

\subsection{Awareness of Locomotive Syndrome}

Awareness was assessed with the following question: "Do you know the term locomotive syndrome?" The response options were "No," "I have heard the term but do not know what it means," and "I have heard the term and know what it means." For the purposes of this study, the responses were sorted into two categories: "No" for the first option, and "Yes" for the other two. This definition of awareness is the same as in Health Japan 21 [21].

\subsection{Participant Characteristics}

Information on sex and age was collected from the town registry. Information was collected from the questionnaire responses on marital status (single, divorced, or widowed/married) and educational attainment (junior high or lower/high school or higher), and also on lifestyle habits: current alcohol drinking habit (no/yes), current smoking habit (no/yes), and weekly exercise habit (less than one hour/one hour or more). To assess the association of awareness of locomotive syndrome with social factors, the participants were asked about their participation in any of the group activities such as local activities (membership of neighborhood associations, women's associations, senior citizens' associations, etc.), sports, hobbies, entertainment activities, volunteer activities, nonprofit organization/citizen activities, voluntary financial cooperative associations, group associations, and other activities (membership of business associations, industry associations, etc.), and responses on all of the above were classified according to the frequency of participation (several times a year in at least one/none). Attendance at any of the following regional events within the previous one year was also recorded (yes, attended at least one/no, or could not remember): health promotion/disease prevention classes, cultural festivals or health welfare festivals, and social education classes. In order to assess the extent of the participants' social interaction, they were asked if they had someone they could talk with about their worries and complaints, about their own health problems, or someone who took care of them when they were sick; they were also asked if they had someone whose worries and complaints they listened to, or someone they took care of when he/she was sick. Responses were categorized as yes for at least one, or no. Relations with neighbors were also assessed: daily contact and cooperation in neighborhood 
chores, or minimal or no contact. From the women, we obtained information about whether they had any experience of health promotion volunteers (none/yes). In Koumi Town, about 65 women have been recruited to work as health promotion volunteers under the supervision of a municipal public health nurse every two years since 1975. They support health promotion activities for families in the local community by, for example, giving recommendations for health examinations.

\subsection{Statistical Analysis}

We used chi-square tests for proportions. Furthermore, the participants were divided into two groups according to their awareness of locomotive syndrome, sex separately, and the baseline variables between the two groups were compared.

The association of awareness of locomotive syndrome with various factors was analyzed sex-separately with two multivariable Poisson regression models, considering the disparities in awareness and background factors between men and women. Model 1 included the basic characteristics of age, marital-status, and educational attainment. Model 2 also included alcohol drinking habit, smoking habit, weekly exercise habit, participation in group activities, attendance at regional events within one year, social support, contact with neighbors, and experience of health promotion volunteering (women only). The strengths of the associations were represented by prevalence ratios (PRs) and 95\% confidence intervals (95\% CIs).

Stata version 14 (Stata Corp., College Station, TX, USA) was used for all analyses.

\section{Results}

\subsection{Participant Characteristics and Awarenss of Locomotive Syndrome}

Significantly more of the participants $(n=1804)$ were in their 60 s and 70 s than the non-participants $(n=1377)$, and women also represented a significantly larger proportion of the participants (Supplementary Table S1). Of the participants, 437 (24.2\%) had heard the term locomotive syndrome but did not know its meaning, and $367(20.3 \%)$ had heard the term and also understood it, meaning that the total awareness proportion was $44.6 \%(804)$. The proportion differed significantly by sex: $32.2 \%$ of the men, compared with $54.4 \%$ of the women $(p<0.001)$. The distributions of age, marital status, and educational attainment were similar in both sexes, but participants who were 60-79 years old, married, and had higher educational attainment showed greater awareness of locomotive syndrome; the women with experience of health promotion volunteers had a significantly higher awareness proportion (Table 1).

\subsection{Prevalence Ratios of Each Covariates to Increase Awarenss of Locomotive Syndrome}

Tables 2 and 3 summarize the adjusted PRs for each factor affecting awareness according to sex. Attendance at regional events within the last one year was significantly associated with awareness of locomotive syndrome in both women and men, with adjusted PRs (95\% CI) in Model 2 of 1.26 (1.10-1.43) and 1.48 (1.19-1.83), respectively. Participation in group activities tended to increase awareness in both sexes. Higher educational attainment was well associated with awareness among the women, and weakly associated among the men. Closer relations with neighbors only showed an association among the women. Additionally, experience of health promotion volunteering (only applicable to women) was significantly associated with awareness (PR (95\% CI) 1.25 (1.09-1.43) in Model 2) (Table 2). On the other hand, lifestyle factors (drinking alcohol, smoking, exercising) were found to have no association with awareness. 
Table 1. Participant characteristics by sex, in association with the awareness of locomotive syndrome.

\begin{tabular}{|c|c|c|c|c|c|c|}
\hline \multirow[b]{3}{*}{ Characteristics } & \multicolumn{6}{|c|}{ Awareness of Locomotive Syndrome } \\
\hline & \multicolumn{3}{|c|}{ Men } & \multicolumn{3}{|c|}{ Women } \\
\hline & $\begin{array}{c}\text { Yes/Total } \\
(n)^{\mathrm{a}}\end{array}$ & $(\%)$ & $p$-Value & $\begin{array}{c}\text { Yes/Total } \\
(n)^{\mathrm{a}}\end{array}$ & $(\%)$ & $p$-Value \\
\hline \multicolumn{7}{|c|}{ All } \\
\hline & $257 / 799$ & $(32.2)$ & & $547 / 1005$ & $(54.4)$ & \\
\hline \multicolumn{7}{|l|}{ Age category } \\
\hline $40-49$ & $25 / 92$ & $(27.2)$ & & $61 / 121$ & $(50.4)$ & \\
\hline $50-59$ & $42 / 149$ & $(28.2)$ & & $94 / 185$ & $(50.8)$ & \\
\hline $60-69$ & $89 / 253$ & $(35.2)$ & & $176 / 268$ & $(65.7)$ & \\
\hline $70-79$ & $67 / 172$ & $(39.0)$ & & $152 / 241$ & $(63.1)$ & \\
\hline 80 or over & $34 / 133$ & $(25.6)$ & 0.050 & $64 / 190$ & $(33.7)$ & $<0.001$ \\
\hline \multicolumn{7}{|c|}{ Merital status } \\
\hline Single/Divorced/Widowed & $44 / 147$ & $(29.9)$ & & $143 / 294$ & $(48.6)$ & \\
\hline Married & $208 / 639$ & $(32.6)$ & 0.540 & $396 / 686$ & $(57.7)$ & 0.009 \\
\hline \multicolumn{7}{|c|}{ Educational attainment } \\
\hline Junior high or lower & $49 / 187$ & $(26.2)$ & & $105 / 278$ & $(37.8)$ & \\
\hline High school or higher & $205 / 600$ & $(34.2)$ & 0.042 & $433 / 705$ & $(61.4)$ & $<0.001$ \\
\hline \multicolumn{7}{|c|}{ Experience of health promotion volunteer } \\
\hline None & & & - & $181 / 408$ & $(44.4)$ & \\
\hline Yes & & & - & $360 / 573$ & $(62.8)$ & $<0.001$ \\
\hline
\end{tabular}

${ }^{a}$ Due to some missing values, the totals for the stratified subgroups are not equal.

Table 2. Adjusted prevalence ratios of each covariates to increase awareness of locomotive syndrome in women.

\begin{tabular}{|c|c|c|c|c|c|c|c|}
\hline & & \multicolumn{2}{|c|}{$\begin{array}{c}\text { Awareness of } \\
\text { Locomotive Syndrome }\end{array}$} & \multirow{2}{*}{$\begin{array}{l}\text { Model } 1 \\
\text { b PR }\end{array}$} & \multirow{2}{*}{$95 \%$ CI $*$} & \multirow{2}{*}{$\begin{array}{l}\text { Model } 2 \\
{ }^{c} \text { PR }^{+}\end{array}$} & \multirow{2}{*}{$95 \% \mathrm{CI}^{*} *$} \\
\hline & & $\begin{array}{l}\text { Yes/Total } \\
(n)^{a}\end{array}$ & $(\%)$ & & & & \\
\hline \multicolumn{8}{|c|}{ Basic characteristics } \\
\hline \multirow{5}{*}{ Age group } & $40-49$ & $61 / 121$ & $(50.4)$ & Ref & & Ref & \\
\hline & $50-59$ & $94 / 185$ & $(50.8)$ & 1.01 & $0.81-1.27$ & 0.92 & $0.73-1.15$ \\
\hline & $60-69$ & $176 / 268$ & $(65.7)$ & 1.34 & $1.10-1.63$ & 1.04 & $0.85-1.28$ \\
\hline & $70-79$ & $152 / 241$ & $(63.1)$ & 1.47 & $1.20-1.80$ & 1.11 & $0.90-1.38$ \\
\hline & 80 or over & $64 / 190$ & $(33.7)$ & 0.83 & $0.62-1.10$ & 0.69 & $0.51-0.94$ \\
\hline \multirow{2}{*}{ Marital status } & $\begin{array}{l}\text { Single/Divorced/ } \\
\text { Widowed }\end{array}$ & $143 / 294$ & $(48.6)$ & Ref & & Ref & \\
\hline & Married & $396 / 686$ & $(57.7)$ & 1.02 & $0.90-1.17$ & 0.99 & $0.86-1.13$ \\
\hline \multirow{2}{*}{$\begin{array}{l}\text { Educational } \\
\text { attainment }\end{array}$} & Junior high or lower & $105 / 278$ & $(37.8)$ & Ref & & Ref & \\
\hline & High school or higher & $433 / 705$ & $(61.4)$ & 1.53 & $1.29-1.81$ & 1.30 & $1.09-1.54$ \\
\hline \multicolumn{8}{|c|}{ Lifestyle } \\
\hline \multirow{2}{*}{$\begin{array}{l}\text { Alcohol drinking } \\
\text { habit }\end{array}$} & No & $353 / 677$ & $(52.1)$ & Ref & & Ref & \\
\hline & Yes & $190 / 322$ & $(59.0)$ & 1.06 & $0.94-1.19$ & 1.02 & $0.91-1.14$ \\
\hline \multirow{2}{*}{ Smoking habit } & No & $525 / 951$ & $(55.2)$ & Ref & & Ref & \\
\hline & Yes & $17 / 43$ & $(39.5)$ & 0.69 & $0.46-1.02$ & 0.69 & $0.44-1.07$ \\
\hline \multirow{2}{*}{ Weekly exercise habit } & Less than one hour & $301 / 683$ & (51.6) & Ref & & Ref & \\
\hline & More than one hour & $217 / 341$ & $(63.6)$ & 1.16 & $1.04-1.30$ & 1.05 & $0.94-1.18$ \\
\hline
\end{tabular}


Table 2. Cont.

\begin{tabular}{|c|c|c|c|c|c|c|c|}
\hline & & \multicolumn{2}{|c|}{$\begin{array}{c}\text { Awareness of } \\
\text { Locomotive Syndrome }\end{array}$} & \multirow{2}{*}{$\underset{\mathbf{b}_{\text {PR }^{+}}^{\text {Model 1 }}}{\text { Mon }}$} & \multirow{2}{*}{$95 \% \mathrm{CI}^{*}$} & \multirow{2}{*}{$\begin{array}{c}\text { Model } 2 \\
{ }^{c} \text { PR }^{+}\end{array}$} & \multirow{2}{*}{$95 \% \mathrm{CI}^{*}$} \\
\hline & & $\begin{array}{c}\text { Yes/Total } \\
(n)^{\mathrm{a}}\end{array}$ & $(\%)$ & & & & \\
\hline \multicolumn{8}{|c|}{ Social Environment } \\
\hline \multirow{2}{*}{$\begin{array}{l}\text { Participation to group } \\
\text { activities }\end{array}$} & None & $125 / 313$ & $(39.9)$ & Ref & & Ref & \\
\hline & Yes & $408 / 657$ & $(62.1)$ & 1.35 & $1.16-1.58$ & 1.13 & $0.95-1.34$ \\
\hline \multirow{2}{*}{$\begin{array}{l}\text { Attendance to } \\
\text { regional events } \\
\text { within one year }\end{array}$} & None/Did not know & $218 / 490$ & $(44.5)$ & Ref & & Ref & \\
\hline & Yes & $320 / 499$ & $(64.1)$ & 1.34 & $1.19-1.50$ & 1.26 & $1.10-1.43$ \\
\hline \multirow{2}{*}{ Social support } & None & $4 / 9$ & $(44.4)$ & Ref & & Ref & \\
\hline & Yes & $538 / 983$ & $(54.7)$ & 0.94 & $0.41-2.14$ & 0.68 & $0.32-1.44$ \\
\hline \multirow{2}{*}{$\begin{array}{l}\text { Closeness to } \\
\text { neighbors }\end{array}$} & None or greetings only & $90 / 228$ & $(39.5)$ & Ref & & Ref & \\
\hline & Daily talk or more & $452 / 765$ & (59.1) & 1.38 & $1.16-1.64$ & 1.20 & $1.01-1.42$ \\
\hline \multirow{2}{*}{$\begin{array}{l}\text { Experience of health } \\
\text { promotion volunteer }\end{array}$} & None & $181 / 408$ & $(44.4)$ & Ref & & Ref & \\
\hline & Yes & 360,573 & $(62.8)$ & 1.31 & $1.15-1.49$ & 1.25 & $1.09-1.43$ \\
\hline \multicolumn{8}{|c|}{$\begin{array}{l}{ }^{\text {a }} \text { Due to some missing values, the totals for the stratified subgroups are not equal. }{ }^{\mathbf{b}} \text { Adjusted by age group, marital } \\
\text { status, and educational attainment. }{ }^{c} \text { Adjusted by all the variables shown in this table. Abbreviations: }{ }^{\dagger} \mathrm{PR} \\
\text { prevalence ratio, }{ }^{*} \text { CI confidence interval. } \\
\text { Table } 3 \text {. Adjusted prevalence ratios of each covariates to increase awareness of locomotive syndrome } \\
\text { in men. }\end{array}$} \\
\hline & & \multicolumn{2}{|c|}{$\begin{array}{c}\text { Awareness of } \\
\text { Locomotive Syndrome }\end{array}$} & \multirow[b]{2}{*}{$\begin{array}{l}\text { Model 1 } \\
\mathbf{b}_{\text {PR }^{+}}\end{array}$} & \multirow[b]{2}{*}{$95 \% \mathrm{CI}^{*}$} & \multirow[b]{2}{*}{$\underset{{ }^{c} \text { PR }^{+}}{\text {Model } 2}$} & \multirow[b]{2}{*}{$95 \% \mathrm{CI} *$} \\
\hline & & $\begin{array}{c}\text { Yes/Total } \\
(n)^{\text {a }}\end{array}$ & $\%$ & & & & \\
\hline \multicolumn{8}{|c|}{ Basic characteristics } \\
\hline \multirow{5}{*}{ Age group } & $40-49$ & $25 / 92$ & $(27.2)$ & Ref & & Ref & \\
\hline & 50-59 & $42 / 149$ & $(28.2)$ & 0.98 & $0.64-1.50$ & 1.00 & $0.66-1.53$ \\
\hline & $60-69$ & $89 / 253$ & $(35.2)$ & 1.33 & $0.92-1.94$ & 1.34 & $0.93-1.95$ \\
\hline & $70-79$ & $67 / 172$ & $(39.0)$ & 1.52 & $1.03-2.24$ & 1.54 & $1.04-2.30$ \\
\hline & 80 or over & $34 / 133$ & $(25.6)$ & 1.11 & $0.70-1.74$ & 1.20 & $0.74-1.94$ \\
\hline \multirow{2}{*}{ Marital status } & Single/Divorced/Widowed & $44 / 147$ & $(29.9)$ & Ref & & Ref & \\
\hline & Married & $208 / 639$ & (32.6) & 1.00 & $0.76-1.32$ & 0.93 & $0.70-1.23$ \\
\hline \multirow{2}{*}{ Educational attainment } & Junior high or lower & $49 / 187$ & $(26.2)$ & Ref & & Ref & \\
\hline & High school or higher & $205 / 600$ & $(34.2)$ & 1.38 & $1.04-1.83$ & 1.28 & $0.96-1.70$ \\
\hline \multicolumn{8}{|c|}{ Lifestyle } \\
\hline \multirow{2}{*}{ Alcohol drinking habit } & No & $80 / 258$ & $(31.0)$ & Ref & & Ref & \\
\hline & Yes & $175 / 538$ & $(32.5)$ & 1.04 & $0.83-1.30$ & 1.04 & $0.83-1.30$ \\
\hline \multirow{2}{*}{ Smoking habit } & No & 199/617 & $(32.3)$ & Ref & & Ref & \\
\hline & Yes & $57 / 181$ & $(31.5)$ & 0.99 & $0.77-1.28$ & 1.01 & $0.79-1.30$ \\
\hline Whollu & Less than one hour & $140 / 439$ & (31.9) & Ref & & Ref & \\
\hline 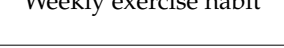 & More than one hour & $110 / 315$ & $(34.9)$ & 1.03 & $0.83-1.27$ & 0.93 & $0.76-1.15$ \\
\hline & & Social Enviror & nent & & & & \\
\hline Participation to group & None & $60 / 223$ & $(26.9)$ & Ref & & Ref & \\
\hline activities & Yes & $195 / 563$ & $(34.6)$ & 1.23 & $0.95-1.59$ & 1.10 & $0.84-1.44$ \\
\hline Attendance to regional & None / Did not know & $154 / 549$ & (28.1) & Ref & & Ref & \\
\hline events within one year & Yes & $102 / 237$ & $(43.0)$ & 1.46 & $1.19-1.80$ & 1.48 & $1.19-1.83$ \\
\hline Cocialannont & None & $7 / 29$ & $(24.1)$ & Ref & & Ref & \\
\hline & Yes & $250 / 768$ & (32.6) & 1.46 & $0.70-3.04$ & 1.29 & $0.64-2.61$ \\
\hline Cloceness to noirb hor & None or greetings only & $59 / 217$ & $(27.2)$ & Ref & & Ref & \\
\hline Choseriess to hergtivoris & Daily talk or more & 198/580 & (34.1) & 1.15 & $0.88-1.50$ & 0.97 & $0.74-1.28$ \\
\hline
\end{tabular}

a Due to some missing values, the totals for the stratified subgroups are not equal. ${ }^{\mathbf{b}}$ Adjusted by age group, marital status, and educational attainment. ${ }^{\mathbf{c}}$ Adjusted by all the variables shown in this table. Abbreviations: ${ }^{\dagger}$ PR prevalence ratio, * CI confidence interval. 


\section{Discussion}

The public awareness of locomotive syndrome in this study was consistent with those of a nationwide internet survey carried out in 2020 [24], showing that awareness is comparatively high among people in their 60s and 70s, when the symptoms of locomotive syndrome become apparent [10-12,25]. The age-related difference of awareness remained after the multivariate adjustment, indicating that the awareness-rising promotion measures need to be focused more on younger people. For these people, educational activities in the workplace may be more effective in increasing awareness than encouraging them to attend regional events. Intervention for this age group is especially important, in order to take preventive measures early enough. On the other hand, the awareness rising activity need to be conducted for elderly people as well, since it has been reported that exercise is effective to some extent to reduce the risk of requiring nursing care even for those who have already developed locomotive syndrome [26]. Home visits and specific guidance targeted at the elderly during regional events may be a good way to increase awareness in this age group.

The difference in awareness between the sexes was more pronounced in our study than in the 2019 nationwide internet survey: we found that $32.2 \%$ of the men and $54.4 \%$ of the women were aware of the term, as compared with $41 \%$ of the men and $48.6 \%$ of the women in the internet survey [23]. The reason for the higher awareness proportion among our female participants may be that $44.4 \%$ of those aged over 40 had experience of health promotion volunteers in Koumi Town. Health promotion volunteering is a traditional activity in Japan, in which volunteers operate under the supervision of a municipal public health nurse [27]. In the Koumi area, only women have been assigned historically. They engage in various activities, such as giving advice on nutrition and promoting blood pressure checks in their community, which is effective in educating them about health issues. Attempts to make people take responsibility for others health in this way may be useful, for men, as well.

It was a novel information that social factors such as attendance at regional health-related events were associated with awareness. Closer relations with neighbors were also significantly associated with awareness among the female participants, indicating that communication with others may play an important role in improving health-related knowledge. However, the direction of causal relationship could not be elucidated from this research. That is, sociable people may have acquired health-related knowledge through regional events and conversations in the neighborhood. In this case, promotion of educational activities at regional events may work to further improve the awareness. On the other hand, there is also a possibility that people with knowledge of locomotive syndrome may be more active in regional health-related events as a result of being aware of importance of active lifestyles; it is a good sign that the recognition lead to the change of life-style. In the latter case, presenting some specific exercise using the place of the regional events may contribute to further improve the musculoskeletal performance of participants.

Looking back, in Japan, awareness of metabolic syndrome has dramatically increased since it was taken up as a basic medical examination item targeting middle-aged and older adult in 2008 [28,29]. According to this, incorporating locomotive syndrome into the health checkup items may be the most effective way to raise awareness. Already, the health-survey for musculoskeletal system has been added to the heath-examination items targeting school children since 2016. In the future, similar approach targeting adults could be useful in raising interest in the musculoskeletal health in younger adults as well as older adults. However, there may still be a hurdle for government to adopt the evaluation of musculoskeletal function as a public health checkup item because locomotive syndrome is not a disease that requires immediate treatment. Moreover, the improvement of the locomotive function may rely largely on individual efforts. Therefore, considering the current social situation, Japan is focusing on raising awareness of the locomotive syndrome, as the first stage to cope with the condition. We believe that our research results are useful as one of the keys to further increase awareness.

Considering the actions to improve the mobility in people, exercises composed of single-leg standing and squatting are recommended from the Japanese Orthopaedic Association and is named Locomotion Training (Locotra) [30]. These exercises aim to strengthen standing and gait functions 
and can be safely performed at home [6]. Additional exercises, stretches, as well as balanced diet that helps strengthen bones and muscles are also recommended by the Japanese Orthopaedic Association [14,30], and various other approaches has been reported as well [31,32]. Though it has not yet been confirmed that musculoskeletal degeneration can be treated by exercise, promoting physical activity appears promising.

The main strength of this study compared to the annual nationwide internet survey $[23,24]$ is that ours is the first community-based cross-sectional study of public awareness of locomotive syndrome. Although the previous internet surveys $[23,24]$ targeted 10,000 men and women over 20 years old, and employed a sampling system that approximately matched participants across prefectures with national census data in terms of population, sex, and age, questions remain about the generalizability of its results: it may, for example, have targeted a smaller proportion of elderly people than exist in the general population, and a larger proportion of technologically savvy people with internet access. Furthermore, internet surveys have data integrity concerns, such as low participation proportions, false answers, and multiple replies from the same respondent [33]. In comparison, our study covered approximately $60 \%$ of the residents aged 40 years or older of a specific area and may well have had a smaller sampling bias than the internet survey. Our research also evaluated the association of awareness of locomotive syndrome with social and lifestyle factors for the first time, providing useful hints on effective ways to increase awareness in the future.

On the other hand, our study has four limitations. First, it might still have been subject to selection bias, because the age and sex of the participants did not match those of the non-participants. There is also a possibility that the survey attracted a disproportionally large number of people who are particularly interested in health issues. Secondly, since the study was conducted in one specific town, it may be difficult to generalize the results to other areas with different living environments. Actually, the nationwide internet survey showed that awareness varies greatly by prefecture. The top three were Saga, with an awareness proportion of $76.9 \%$, Miyazaki at $64.0 \%$, and Tokushima at $58.5 \%$; the lowest was Shizuoka, with a proportion of 34.6\% [23]. It is difficult to say whether this discrepancy between prefectures resulted from selection bias (the top three prefectures all have small populations, so only a small number of people were surveyed from each one), or from differences in the degree of effort made by local municipalities to increase awareness. Thirdly, since the information was collected via questionnaire, there would be information biases such as recall bias. There could also be mistakes by participants while answering the questionnaire. Lastly, as mentioned earlier, since this is a cross-sectional study, different study is needed to elucidate the direction of causal relationship.

\section{Conclusions}

An association between social factors, especially attendance at regional events, and awareness of locomotive syndrome was revealed. In addition to strengthen awareness rising campaigns targeting men and for younger people, providing health education at social settings such as regional events may help improve future musculoskeletal health in the elderly.

Supplementary Materials: The following are available online at http://www.mdpi.com/1660-4601/17/19/7272/s1, Table S1: Comparison of age and sex of study participants and non-participants.

Author Contributions: Conceptualization, K.S., H.I., T.M., K.A., and Y.N.; methodology, H.I., T.M., and Y.N.; investigation, H.I.; data curation, K.S., H.I., and T.M.; writing-original draft preparation, K.S.; writing-review and editing, K.S., H.I., T.M., K.A., and Y.N; supervision, Y.N.; project administration, Y.N.; funding acquisition, H.I. All authors have read and agreed to the published version of the manuscript.

Funding: This research was funded by the Grants-in-Aid for Scientific Research of Japan Society for the Promotion of Science, grant number 17K15858.

Acknowledgments: We express our gratitude for the cooperation and support provided by the Health Section, Resident Life Department, Koumi Town Hall, Nagano Prefecture, Japan.

Conflicts of Interest: The authors declare no conflict of interest. 
Availability of Data and Materials: The datasets generated and analyzed during the current study are not publicly available because we did not receive consents for data provision to the third party.

\section{References}

1. United Nations, Department of Economic and Social Affairs, Population Division. World Population Ageing 2019: Highlights; United Nations: New York, NY, USA, 2019.

2. Statistics Bureau of Japan. Population Estimates by Age (aFive-Year Goups) and Sex (2019. Nov. 1st). Available online: https://www.stat.go.jp/data/jinsui/pdf/201911.pdf (accessed on 9 April 2020).

3. Song, P.; Tang, W. The community-based integrated care system in Japan: Health care and nursing care challenges posed by super-aged society. Biosci Trends 2019, 13, 279-281. [CrossRef] [PubMed]

4. Ministry of Health, Labour and Welfare. From Comprehensive Survey of Living Conditions, 2016. Graphical Review of Japanese Household; Ministry of Health, Labour and Welfare: Tokyo, Japan, 2018.

5. Nakamura, K. A "super-aged" society and the "locomotive syndrome". J. Orthop. Sci. 2008, 13, 1-2. [CrossRef] [PubMed]

6. Nakamura, K.; Ogata, T. Locomotive Syndrome: Definition and Management. Clin. Rev. Bone Miner. Metab. 2016, 14, 56-67. [CrossRef] [PubMed]

7. Nakamura, K. Locomotive Syndrome: The Concept and Recent Topics. Jpn. J. Rehabil. Med. 2016, 53, 890-893. [CrossRef]

8. Nakamura, M.; Kobashi, Y.; Hashizume, H.; Oka, H.; Kono, R.; Nomura, S.; Maeno, A.; Yoshida, M.; Utsunomiya, H. Locomotive syndrome is associated with body composition and cardiometabolic disorders in elderly Japanese women. BMC Geriatr. 2016, 16, 166. [CrossRef]

9. Yoshimura, Y.; Ishijima, M.; Ishibashi, M.; Liu, L.; Arikawa-Hirasawa, E.; Machida, S.; Naito, H.; Hamada, C.; Kominami, E. A nationwide observational study of locomotive syndrome in Japan using the ResearchKit: The Locomonitor study. J. Orthop. Sci. 2019, 24, 1094-1104. [CrossRef]

10. Yamada, K.; Ito, Y.M.; Akagi, M.; Chosa, E.; Fuji, T.; Hirano, K.; Ikeda, S.; Ishibashi, H.; Ishibashi, Y.; Ishijima, M.; et al. Reference values for the locomotive syndrome risk test quantifying mobility of 8681 adults aged 20-89 years: A cross-sectional nationwide study in Japan. J. Orthop. Sci. 2020. [CrossRef]

11. Yoshimura, N.; Muraki, S.; Iidaka, T.; Oka, H.; Horii, C.; Kawaguchi, H.; Akune, T.; Nakamura, K.; Tanaka, S. Prevalence and co-existence of locomotive syndrome, sarcopenia, and frailty: The third survey of Research on Osteoarthritis/Osteoporosis Against Disability (ROAD) study. J. Bone Miner. Metab. 2019, 37, 1058-1066. [CrossRef]

12. Yoshimura, N.; Muraki, S.; Nakamura, K.; Tanaka, S. Epidemiology of the locomotive syndrome: The research on osteoarthritis/osteoporosis against disability study 2005-2015. Mod. Rheumatol. 2017, 27, 1-7. [CrossRef]

13. Yoshimura, N.; Muraki, S.; Oka, H.; Mabuchi, A.; En-Yo, Y.; Yoshida, M.; Saika, A.; Yoshida, H.; Suzuki, T.; Yamamoto, S.; et al. Prevalence of knee osteoarthritis, lumbar spondylosis, and osteoporosis in Japanese men and women: The research on osteoarthritis/osteoporosis against disability study. J. Bone Miner. Metab. 2009, 27, 620-628. [CrossRef]

14. Ishibashi, H. Locomotive syndrome in Japan. Osteoporos Sarcopenia 2018, 4, 86-94. [CrossRef] [PubMed]

15. Evans, W.J. Effects of exercise on body composition and functional capacity of the elderly. J. Gerontol. A Biol Sci. Med. Sci. 1995, 50, 147-150. [PubMed]

16. Faber, M.J.; Bosscher, R.J.; Chin, A.P.M.J.; van Wieringen, P.C. Effects of exercise programs on falls and mobility in frail and pre-frail older adults: A multicenter randomized controlled trial. Arch. Phys. Med. Rehabil. 2006, 87, 885-896. [CrossRef] [PubMed]

17. Binder, E.F.; Schechtman, K.B.; Ehsani, A.A.; Steger-May, K.; Brown, M.; Sinacore, D.R.; Yarasheski, K.E.; Holloszy, J.O. Effects of exercise training on frailty in community-dwelling older adults: Results of a randomized, controlled trial. J. Am. Geriatr. Soc. 2002, 50, 1921-1928. [CrossRef]

18. Ramachandran, H.J.; Wu, V.X.; Kowitlawakul, Y.; Wang, W. Awareness, knowledge and healthy lifestyle behaviors related to coronary heart disease among women: An integrative review. Heart Lung 2016, 45, 173-185. [CrossRef]

19. Sybilski, A.J.; Lusawa, A.; Lipiec, A.; Piekarska, B.; Raciborski, F.; Krzych-Falta, E.; Tomaszewska, A.; Samolinski, B. The effects of disease awareness on lifestyle changes and the use of preventive measures in asthma patients. Allergy Asthma Proc. 2015, 36, e14-e22. [CrossRef] 
20. Uemura, K.; Yamada, M.; Okamoto, H. Effects of Active Learning on Health Literacy and Behavior in Older Adults: A Randomized Controlled Trial. J. Am. Geriatr. Soc. 2018, 66, 1721-1729. [CrossRef]

21. Yoko Komiyama MoH, Labour and Welfare. Yoko Komiyama, Minister of Health, Labour and Welfare, Ministerial Notification No. 430 of the Ministry of Health, Labour and Welfare. Updated 10 July 2012. Available online: https://www.mhlw.go.jp/file/06-Seisakujouhou-10900000-Kenkoukyoku/0000047330.pdf (accessed on 25 May 2020).

22. Sugiyama, K.; Toyama, Y.; Takemi, Y.; Tsushita, K.; Nakamura, M.; Hashimoto, S.; Miyachi, M.; Yamagata, Z.; Yokoyama, T.; Tsuji, I. Awareness and health consciousness regarding the national health plan "Health Japan 21" (2nd edition) among the Japanese population in 2013 and 2014. Jpn. J. Public Health. 2016, 63, 424-431.

23. Awareness Survey of Locomotive Syndrome 2019. The Bone and Joint Decade Japan. Published 2019 (In Japanese). Available online: https://www.bjd-jp.org/wp/wp-content/uploads/2019/04/2019.pdf (accessed on 20 July 2020).

24. Awareness Survey of Locomotive Syndrome 2020. The Bone and Joint Decade Japan. Published 2020 (In Japanese). Available online: https://www.bjd-jp.org/archives/news/1235 (accessed on 21 July 2020).

25. Muraki, S.; Oka, H.; Akune, T.; Mabuchi, A.; En-Yo, Y.; Yoshida, M.; Saika, A.; Suzuki, T.; Yoshida, H.; Ishibashi, H.; et al. Prevalence of radiographic lumbar spondylosis and its association with low back pain in elderly subjects of population-based cohorts: The ROAD study. Ann. Rheum. Dis. 2009, 68, 1401-1406. [CrossRef]

26. Fujino, K. The effectiveness of rehabilitation training on the care recipient (Japanese). Biomed. Ther. 2010, 44, 97-99.

27. Imamura, H.; Nakamura, H.; Nishiwaki, Y. Relationship between the Well-Being of Elderly Men and Cohabiting with Women Who Have Had Experience as a Health Promotion Volunteer in Japan: A Cross-Sectional Study. Int. J. Environ. Res. Public Health 2018, 16, 65. [CrossRef]

28. Nakao, Y.M.; Miyamoto, Y.; Ueshima, K.; Nakao, K.; Nakai, M.; Nishimura, K.; Yasuno, S.; Hosoda, K.; Ogawa, Y.; Itoh, H.; et al. Effectiveness of nationwide screening and lifestyle intervention for abdominal obesity and cardiometabolic risks in Japan: The metabolic syndrome and comprehensive lifestyle intervention study on nationwide database in Japan (MetS ACTION-J study). PLoS ONE 2018, 13, e0190862. [CrossRef] [PubMed]

29. Tsushita, K.A.S.H.; Miura, K.; Ito, Y.; Fukuda, T.; Kitamura, A.; Tatara, K. Rationale and Descriptive Analysis of Specific Health Guidance: The Nationwide Lifestyle Intervention Program Targeting Metabolic Syndrome in Japan. J. Atheroscler. Thromb. 2018, 25, 308-322. [CrossRef] [PubMed]

30. The Japanese Orthopaedic Association, Locomotive Syndrome Pamphlet 2015. Available online: https: //locomo-joa.jp/assets/pdf/index_english.pdf (accessed on 5 September 2020).

31. Kato, S.; Demura, S.; Kurokawa, Y.; Takahashi, N.; Shinmura, K.; Yokogawa, N.; Yonezawa, N.; Shimizu, T.; Kitagawa, R.; Tsuchiya, H. Efficacy and Safety of Abdominal Trunk Muscle Strengthening Using an Innovative Device in Elderly Patients With Chronic Low Back Pain: A Pilot Study. Ann. Rehabil. Med. 2020, 44, 246-255. [CrossRef]

32. Sato, H.; Kondo, S.; Saito, M.; Saura, R. Effects of strengthening the hip flexor muscles on walking ability and the locomotive syndrome rank test: An intervention study. J. Orthop. Sci. 2019. [CrossRef] [PubMed]

33. Hays, R.D.; Lu, H.; Kapteyn, A. Use of Internet Panels to Conduct Surveys. Behav. Res. Methods 2015, 47, 685-690. [CrossRef] [PubMed]

(C) 2020 by the authors. Licensee MDPI, Basel, Switzerland. This article is an open access article distributed under the terms and conditions of the Creative Commons Attribution (CC BY) license (http://creativecommons.org/licenses/by/4.0/). 